\title{
KEPAHLAWANAN PADA NASKAH DRAMA LAKSAMANA HANG TUAH KARYA TENAS EFFENDI
}

\author{
Tengku Muhammad Sum*), Evizariza**) \\ Fakultas Ilmu Budaya, Universitas Lancang Kuning, Pekanbaru, Indonesia \\ Email: tengkumuhammadsum@gmail.com*), evizariza@unilak.ac.id **)
}

\begin{abstract}
Abstrak
Tujuan Penelitian ini adalah mendeskripsikan kepahlawanan pada naskah drama "Laksamana Hang Tuah" karya Tenas Effendi. Peristiwa sejarah yang terjadi dalam sebuah kehidupan manusia, yaitu sejak zaman dahulu sampai zaman modern sekarang ini. Kita selalu melihat suatu pertentangan yang terjadi antara satu tokoh penting dengan tokoh lainnya di masyarakat yang ada. Masing masing tokoh tersebut seperti membawa kebenarannya di dalam bertindak, akibat sikap para tokoh yang berbeda pandangan tersebut tidak dapat diselesaikan dengan perundingan yang baik maka diambilah sikap yang tegas yang diselesaikan dengan pertarungan fisik. Maka, terjadilah suatu pertarungan antara Hang Tuah dengan Hang Jebat. Suatu pertarungan antara kebaikan dan kejahatan yang selalu saja terjadi di dunia ini, tentu saja di dalam pertarungan tersebut ada yang kalah dan ada pula yang menang. Kita hanya bisa mengambil suatu hikmah dan suatu pelajaran yang sangat berharga dari pertarungan tersebut. Pertentangan antara Hang Tuah dengan Hang Jebat adalah suatu contoh kasus yang ada pada masa kerajaan Melaka di semenanjung melayu. Suatu pertarungan lama yang terjadi pada masa kerajaan Melaka. Masing-masing tokoh mempunyai alasannya masing masing, yang tak dapat lagi di selesaikan dengan perundingan. Akhirnya persoalan itu di selesaikan dengan perkelahian yang seru. Salah satunya mesti ada yang gugur di dalam pertarungan itu.
\end{abstract}

Kata Kunci: Kepahlawanan, Laksamana Hang Tuah, Naskah Drama.

\begin{abstract}
The purpose of this study was to describe heroism in the drama script "Admiral Hang Tuah" by Tenas Effendi. Historical events that occur in a human life, from ancient times to modern times today. We always see a conflict that occurs between one important figure and another in the community. Each of these figures is like bringing the truth in action, due to the attitude of the different figures that view cannot be resolved by good negotiations, so a firm attitude is resolved through physical battles. There was a battle between Hang Tuah and Hang Jebat. A fight between good and evil that always happens in this world, of course in the fight there are those who lose and some win. We can only take a lesson lesson from the fight. The conflict between Hang Tuah and Hang Jebat is a case in point in the kingdom of Melaka on the Malay peninsula. An old battle that took place during the kingdom of Melaka. Each figure has their own reasons, which can no longer be resolved by negotiations. Finally the problem was solved by an exciting fight. One of them must be killed in the fight.
\end{abstract}

Keywords: Heroism, Admiral Hang Tuah, Drama Script.

\section{Pendahuluan}

Karya sastra tidak lahir dari kekosongan budaya. Dengan media bahasa, karya sastra hadir sebagai cerminan realitas sosial yang dipotret pengarangnya. Tidak sekadar ada, karya sastra juga merespon kondisi sosial yang ada dan berusaha memberikan faedah bagi pembacanya. Karya sastra yang tinggi adalah karya sastra yang mampu membangun kekuatan nurani dan memberi semangat untuk menjalani hidup.

Drama merupakan suatu karya sastra yang ditulis dalam bentuk dialog dan dengan maksud dipertunjukkan oleh aktor. Pementasan naskah drama dapat dikenal dengan istilah teater. Drama juga dapat dikatakan sebagai cerita yang 
diperagakan di panggung dan berdasarkan sebuah naskah.

Pada umumnya, drama memiliki 2 arti, yaitu drama dalam arti luas serta drama dalam arti sempit. Pengertian drama dalam arti luas adalah semua bentuk tontonan atau pertunjukkan yang mengandung cerita yang ditontonkan atau dipertunjukkan di depan khalayak umum. Sedangkan pengertian drama dalam arti sempit ialah sebuah kisah hidup manusia dalam masyarakat yang diproyeksikan di atas panggung.

Drama menurut kata seorang filsup adalah perbenturan antara satu tese yang satu dengan suatu tese lainnya yang lebih tinggi kadarnya. Di dalam panggung kehidupan yang besar ini. Kalau di dalam teori drama , peristiwa peristiwa yang terjadi sehari hari adalah peristiwa drama murni. Kalau boleh meminjam istilah sastrawan Indonesia Taufik Ismail. Dunia ini panggung sandiwara ceritanya mudah berubah, yang selalu dinyanyikan group band God Bless yang terkenal itu. Di dalam panggung hikayat sejarah melayu kita sudah mengenal dengan baik tokoh-tokoh seperti Hang Tuah di dalam sejarah melayu adalah seorang pahlawan legendaris dari tanah semenanjung melayu yang seorang tokoh protogonis dan seorang tokoh lainnya yang merupakan suatu tokoh antogonis. Yang di lengkapi tokoh-tokoh pembantu lainnya. Yaitu Hang Lekir, Hang Kasturi, Hang Lekiu. Yang mana pertentangan antara Hang Tuah dan Hang Jebat menjadi. Suatu perbenturan klasik dua tokoh yang masing-masing mempunyai argumentasinya masing-masing, yang mana alasannya itu masih menjadi perbincangan yang tidak pernah habisnya habisnya oleh para peneliti dan sastrawan yang ada di wilayah melayu. Di masyarakat yang ada di semenanjung melayu dan juga di daerah Riau khususnya. Dari zaman kerajaan kejayaan Melaka sampai dengan sekarang ini perbincangan ini terus saja terjadi. ada juga segelintir sastrawan yang mengangkat Hang Jebat sebagai tokoh kesatria, bukan di anggap sebagai tokoh pemberontak. Ini sebenarnya soal lain lagi, hal tersebut kita anggap saja sebagai suatu anti tese dari hikayat sejarah Hang Tuah itu.

Kesetiaan dan pengabdian yang sungguhsungguh dari Hang Tuah kepada sultan Mansyur syah. Menyebabkan ia disayangi Raja dari pembesar-pembesar kerajaan lainnya. Hal inilah menjadi awal petaka di dalam kerajaan Melaka. Patih Karma Wijaya seorang panglima pasukan angkatan darat kerajaan Melaka merasa iri dan dengki kepada Hang Tuah. Dengan segala kelicikannya dengan penggawa setianya, ia membuat fitnah terhadap Hang Tuah, bahwa Hang Tuah telah berbuat serong dengan Tun Teja istri baginda sultan.

Berita fitnah yang disebarkan patih Karma Wijaya telah membuat amarah baginda raja. Dengan tipu daya dan kelicikannya, ia berhasil menghasut baginda raja. Tanpa ada usul periksa lagi, baginda raja menjatuhkan hukuman mati bagi Hang Tuah. Hukuman mati itu di serahkan kepada datuk bendahara. Selaku pembesar istana penegak hukum di kerajaan. Walaupun sebenarnya Hang Tuah tidak jadi di hukum bunuh karena kebijaksanaan dari datuk bendahara, Inilah awal bencana itu yang terjadi di kerajaan Melaka. Hang Jebat yang merupakan saudara seperguruan Hang Tuah tidak bisa menerima kenyataan ini. Ia menjadi dendam kepada baginda raja. Kesetiaannya yang sangat kuat pada Hang Tuah itu, ia rela mendurhaka kepada baginda raja. Istana kerajaan Melaka di kuasainya, ia berbuat sewenang wenang lalu melepaskan amarahnya di dalam istana. Sedangkan baginda raja untuk sementara waktu mengungsi ke rumah datuk Bendahara. Di dalam keadaan yang sangat sulit ini. Datuk Bendahara menjelaskan kepada baginda raja, sebenarnya Hang Tuah itu masih hidup dan di sembunyikan pada suatu tempat. Baginda raja gembira mendengar berita ini, maka disuruhlah Hang Tuah untuk mengamankan dan meredam Hang Jebat yang mengamuk di istana kerajaan Melaka.

Kalau kita pandang secara jernih persoalan ini, dan paham dengan simbol-simbol suatu kerajaan Melayu. Yang ada pada adat istiadat Raja-Raja dahulu kala bahwa setiap orang yang memberontak dan mengamuk di istana raja, apalagi di singgasana kerajaan Melayu. Maka orang yang mengamuk dan memberontak itu seperti yang dilakukan Hang Jebat, adalah suatu kesalahan yang amat fatal dan durhaka kepada sultan dan kerajaan.

Tidak salah kalau raja memerintahkan Hang Tuah untuk menghukum Hang Jebat dengan pertarungan yang seru dan akhirnya Hang Jebat berhasil dikalahkan oleh Hang Tuah. Sebenarnya apa yang dilakukan oleh sultan Melaka dengan tujuan hanya satu yaitu untuk menyelamatkan marwah kerajaan Melaka dan rakyat jelata khususnya. Hang Tuah sangat sulit untuk membuat satu pilihan itu. Seperti memakan buah simalakama dimakan mati bapak tak dimakan mati ibu .Di lain pihak ia terikat sumpah setia kepada raja dipihak yang lain ia bersaudara seperguruan dengan Hang Jebat sejak kecil sampai dewasa. Antara sumpah setia 
kepada Raja dan persaudaraan. Akhirnya Hang Tuah harus membuat keputusan yang tegas yaitu membunuh Hang Jebat demi marwah kerajaan melayu itu sendiri dan kepentingan rakyat banyak yang harus mengenyampingkan kepentingan pribadi. Makanya tidak salah kalau Hang Tuah ditetapkan sebagai pahlawan Melayu di semenanjung Melayu dan di daerah Melayu Riau. Menurut Zuriati pahlawan bermakna orang yang menonjol karena keberanian dan pengorbanannya dalam membela kebenaran atau pejuang yang gagah berani. Kepahlawanan adalah perihal sifat pahlawan, seperti keberanian, kerelaan berkorban, dan kesatriaan keperkasaan(2005:36).

Sisi lain dari pandangan Hang Jebat yaitu dia mengingatkan pula bahwa raja yang semenamena boleh saja disanggah tetapi bukan dengan cara-cara yang liar, seperti mengamuk di singgasana kerajaan. Tapi hal tersebut bisa saja disampaikan kepada para petinggi-petinggi istana yang ada di kerajaan itu. Karena itulah, pendurhakaan Hang Jebat kepada sultan tidak bisa diterima ditatanan masyarakat Melayu pada umumnya. Menurut Hasanudin Ws, Hang Tuah yang telah dinobatkan sebagai Laksamana yang telah berbakti secara optimal kepada baginda raja dan kerajaan, itulah yang menunjukkan Hang Tuah sebagai pahlawan. Dari sikap Hang Tuah yang konsisten itu dapat kita lihat bahwa Hang Tuah baktinya terhadap raja dan kerajaan memang luar biasa. Demi Baginda Raja dan kerajaan ia sanggup membunuh sahabat seperguruannya sendiri untuk menciptakan perdamaian dan ketenangan di kerajaan Melaka.

\section{Sinopsis}

Pada masa kejayaan pemerintahan kerajaan sultan Melaka pada sekitar abad ke 15, kesultanan Melayu Melaka, yang bermula pada tahun 1400-1511. Menurut sejarahnya. Hang Tuah yang lahir di kampung sungai Duyung sekitar tahun 1444. Ayahnya bernama Hang Mahmud ibunya bernama Dang Merdu Wati. Ayahnya adalah hulubalang istana yang sangat terkenal dan di segani pada zaman itu. Begitu pula ibunya Dang Merdu Wati seorang keturunan dayang istana. Hang Tuah mempunyai saudara seperguruan yaitu, Hang Jebat, Hang Lekir, Hang kasturi, Hang Lekeu, mereka berlima pernah berguru dengan Adi Putra di gunung Ledang. Setelah mereka berlima tamat menuntut ilmu di gunung Ledang tersebut, mereka kembali ke kota Melaka. Di kota Melaka mereka berlima melihat datuk Bendahara yang di serang seorang lelaki yang sedang mengamuk di pasar.Lalu mereka berlima bersaudara seperguruan itu mengamankan lelaki tersebut.
Datuk bendaharapun sangat kagum dengan ketangkasan dan keterampilan mereka berlima.Karena itulah Menjemput Hang Tuah dan saudara seperguruannya ke rumah datuk bendahara, dan rencana datuk bendahara adalah menjadikan mereka berlima untuk bertugas di istana kerajaan Melaka.

Sejak saat itu Hang Tuah dan sahabat sahabatnya amat disayangi oleh baginda Raja sehingga Hang Tuah mendapat gelar Laksamana. Singkat cerita telah terjadi kesalahpahaman antara Hang Tuah dengan baginda Raja akibat fitnah yang di sebarkan oleh patih Karma Wijaya, akibat fitnah itu Hang tuah di sembunyikan di hulu Melaka. Oleh datuk bendahara karena ada berita Hang Tuah dihukum mati oleh sultan maka , Hang Jebat karena rasa sayangnya kepada Hang Tuah sebagai saudara seperguruan ia menutut balas kepada sultan yang telah menghukum bunuh Hang Tuah. Sebab itulah Hang Jebat mengamuk di istana, semua pembesar - pembesar istana tidak sanggup menghadapi amukan Hang Jebat di dalam istana yang dianggap durhaka kepada raja. Tidak ada satupun yang berani menghalagi dan menghadapi tingkah laku Hang Jebat. Lalu datuk bendahara membuka rahasia kepada baginda Raja bahwa, Hang Tuah masih hidup beliau berada di dusun. Maka atas titah raja Melaka Hang Tuah di suruh kembali ke kerajaan untuk menghadapi Hang Jebat. Raja Melaka sangat gembira menyambut kepulangan Hang Tuah. Baginda Raja memberikan harapan dan sangat kasih dengan Hang Tuah.Baginda Raja menitahkan kepada Hang Tuah agar beradu tenaga dan ilmu dengan Hang Jebat. Karena baginda sudah tidak tahan dengan pendurhakaan Hang Jebat kepada Raja. Sebelum beradu dengan Hang Jebat, Hang Tuah minta istirahat selama lima hari untuk memulihkan tenaga. Hang Tuah juga menyarankan kepada raja, keris tameng sari di serahkan kepadanya. Tetapi keris tameng sari pada saat sekarang ini di tangan Hang Jebat.Tidak ada seorangpun yang dapat mengambil keris Tameng Sari . Baginda Raja mencadangkan agar Hang Tuah menggunakan keris baginda yang lain. Hang Tuah mencoba semua keris baginda Raja, tetapi tidak satupun keris yang bisa menandingi keris Tameng Sari itu. Akhirnya Raja Melaka menitahkan Hang Kasturi mengambil keris yang di anugrahkan oleh ayahndanya di bukit Seguntang buat Hang Tuah. di istana Melaka Hang Jebat menyambut baik kedatangan Hang Kasturi sebab hubungan Hang Jebat dan Hang kasturi sudah lama terjalin persahabatan sudah lama sejak mereka masih kecil . Hang Jebatpun mengambil keris pusaka itu dan menyerahkan kepada Hang Kasturi. 
Keesokan hari nya sewaktu Hang Jebat masih tidur, Hang Tuah di iiringi 40 orang pengawal dan berbekal keris pusaka raja Melaka pergi ke istana melawan Hang Jebat. Hang jebat terjaga dari tidurnya apabila terdengar suara huru hara suara dayang dayang istana 700 orang penuh bising dan ketakutan, kehadiran Hang Tuah di tengah- tengah taman istana sangat mengejutkan Hang Jebat. Beliau menganggapnya hanya mimpi karena beliau menganggap Hang Tuah telah mati di bunuh.

Sebelum Hang Tuah memasuki istana Hang Jebat menutup semua pintu istana dan membunuh semua perempuan perempuan dalam istana kecuali Dang Baru yang mengandung tujuh bulan. Hang tuah menyuruh Hang Jebat membuka ke dua dua daun pintu. Karena khawatir dengan tipu helahnya Hang Jebat. Hang Tuah pun melompat ke dalam istana bermulalah perkelahian dua orang sahabat tersebut. Dalam perkelahian tersebut Hang Tuah gagal untuk menikam Hang Jebat karena keris Tameng Sari masih berada di tangan Hang jebat sebelum meneruskan pertikaman. Hang Jebat meminta semua pengawal istana tidak menjolok lantai istana dengan lembing ia memberi tahu kehamilan Dang Baru. Dua bersaudara sepergurauan ini terpaksa bertarung di atas talam, karena khawatir dijolok dari bawah lantai istana. Kemudian beliau berwasiat kepada Hang Tuah jika Dang Baru melahirkan anak lelaki hendaklah dijadikan pengawal Tun Nadim[ anak Hang Tuah] mana kala perempuan terserah ibunya Dang Baru.Apabila mereka penat bertarung dua besaudara itupun berehat sejenak.Hang Jebat terleka waktu beristirahat, dan kesempatan itu diambil Hang Tuah untuk mengambil keris tameng sari ndipinggang Hang Jebat. Hang Tuah membalingkan keris yang digunakannya sebelum ini ke arah Hang Jebat dan pergelutan diteruskan, Hang Jebatpun telah tertikam keris tameng sari Hang Tuah, setelah pertarungan dan pergelutan terakhir. Hang Tuah membalut luka Hang Jebat terlebih dahulu sebelum pulang ke rumah.

Hang jebat yang bermandikan darah menutup semua pintu istana untuk berehat dan berjumpa istrinya. Orang ramai menyaksikan pertikaman tersebut, mereka terkejut karena Hang Jebat masih hidup. Hang jebat kemudian mengamuk di tengah pasar negeri Melaka menyebabkan beribu ribu orang mati terbunuh termasuk lelaki dan perempuan.

Hang Kasturi menjenguk Hang Tuah di rumahnya atas titah baginda Raja Melaka. Hang kasturi diberi tahu Dang Kamala bahwa Hang
Tuah sedang berkhalwat dan tidak boleh bercakap- cakap selama tiga hari tiga malam.Berita tersebut di sampaikan kepada baginda raja. Hang Tuahpun kemudian pergi ke sungai setelah mendapat tahu tentang mengamuknya Hang Jebat di pasar.

Setelah Hang Jebat mengamuk terdengar suara Hang Tuah, beliau terus mendapakan Hang Jebat dan meminta supaya dirinya dibuang ke sungai. Hang tuah merasa simpati dengan Hang Jebat, lalu membawanya bersama pulang ke rumah. Hang Tuah membawanya pulang ke rumah. Hang Tuah memberinya sirih yang sudah beliau kapurkan . Hang Jebat meminta agar Hang Tuah membuka balutan luka darahpun keluar dengan banyaknya. Tidak lama kemudian Hang jebat pun mati di pangkuan Hang Tuah.

Mayat Hang Jebat digantung di tengah tengah jalan besar selama lebih kurang tujuh hari tujuh malam. Untuk dijadikan totonan ramai, Raja Melaka bertambah sayang kepada Hang Tuah dan ini menimbulkan perasaan iri hati para pegawai dan pertinggi petinggi di istana Melaka. Tetapi tidak berani untuk menyuarakannya, karena bendahara dan Temenggong sangat sayang dengan Hang Tuah.

Dang Baru melahirkan anak lelaki yang diberi nama Hang Nadim setelah dua bulan Hang Jebat meninggal. Raja memerintahkan supaya Hang Nadim dibuang ke laut. Tetapi di halangi Hang Tuah karena Hang Jebat berwasiat agar anak itu dipeliharanya Hang Tuah menghadap Tun Teja memohon kurnia supaya Hang Nadim itu di antar ke Inderapura untuk di jaga ayahnda Tun Teja.

\section{Pembahasan}

Dialog- dialog yang terjadi di dalam teks naskah Hang Tuah, Suatu pertengkaran yang keras dan tegas masing- masing tokoh mempertahankan pendapatnya masing-masing. Jelas sekali hitam putihnya, disuatu pihak Hang Tuah sangat setia terhadap baginda sultan sesuai dengan janji yang diucapkan mereka berlima dahulu, setia mengabdi sepanjang hayat kepada baginda sultan. Hang Jebat juga sangat setia sebagai saudara angkat dan seperguruan dengan Hang Tuah. Karena kesetiaan itulah Hang Jebat mendurhaka kepada baginda Raja. Masing masing mempunyai alasan dengan kebenarannya sendiri. Tidak ada kesesuian pendapat antara satu sama lainnya, sehingga pertentangan itu terjadi sangat keras dan tajam . Masing masing pihak tidak ada satupun yang mau mengalah .Pertengkaran yang terjadi itu tidak ada lagi penyelesaian. Pada puncaknya tidak ada jalan 
lain . Di selesaikan dengan suatu cara lelaki yang ksatria, yaitu suatu pertarungan fisik yang seru. Beradu silat dan ketangkasan antara Hang Tuah dengan Hang Jebat, yang mesti ada di antara keduanya yaitu kalah atau menang. Gugur salah satu diantara mereka berdua.

\section{1 Hangtuah :}

Hoooi jebat!

Kenapa tiada lagi setiamu kepada rajamu.

Adat panglima sejak dahulu

Tiada menjilat ludahnya.

Berdasarkan data di atas Hang Tuah dengan tegas mengingatkan kepada Hang Jebat , perjanjian awal dahulu sewaktu berada di Melaka. Mereka berlima bersaudara seperguruan bersumpah setia kepada raja Melaka mengabdi sepanjang umur.

3.2 Hang Jebat : (Terperanjat mendengar suara itu) ia

Kenal bahwa suara itu adalah suara Hang

Tuah. Tetapi

Menurut tahuku Hang Tuah telah tiada.

Sejurus ia Tertegun. Lalu memendang berkeliling mencari sumber Suara itu. Tetapi ia tidak melihat apa apa. Kemudian ia

Tertawa terbahak bahak.

Ha.........ha....... Suara siapakah itu?

Kalau engkau lelaki keluarlah.

Jangan menipu dari jauh.

Hang jebat merasa kesal dengan suara yang ia dengar dari kejauhan itu.sebab tidak nampak orangnya ada terdengar suaranya.Dan Hang Jebat mencari cari suara tersebut di setiap sudut istana.

\subsection{Hang Tuah :}

Hoooi Jebat!

Sia-sia engkau setia selama ini,

Sungguh beranimu tiada berlawan

Keris sakti di pinggangmu, hadiah batara

Majapahit

Bukanlah untuk membunuh kawan.

Tetapi sebagai pelindung negeri.

Data di atas menjelaskan bahwa Hang Tuah dengan lantang dan tegas mengingatkan lagi kepada Hang Jebat, bahwa keris yang ia pegang itu adalah untuk mempertahankan negeri dari serangan musuh yang datang dari luar.bukan membunuh orang yang ada di dalam kerajaan Melaka khususnya lagi di dalam istana.
3.4 Hang Jebat: (Berpaling menjelajahi sekelililng tetapi siapa yang berkata belum dilihatnya)

Cih, siapakah itu.

Si jebat hanya tunduk pada keadilan,

Kalau pohon membawa rebah,

Si jebat tak sudi menyembah Raja.

Dengan marahnya hang jebat mengatakan ia hanya tunduk dengan raja yang adil di kerajaan, ia tidak lagi setia kepada raja Melaka yang tidak adil kepada saudaranya hang tuah.

3.5 Hang Tuah: (Kelihatan berjalan perlahan lahan ke panggung Ia berjalan sendirian, langkahnya tegas dan pasti)

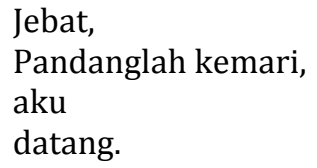

Berdasarkan data di atas Hang Tuah berkata pada Hang Jebat, bahwa ia masih hidup. karena itu Hang Tuah datang menjumpai Hang Jebat, untuk menyelesaikan masalah yang terjadi di kerajaan.

\subsection{Hang Jebat :}

(setelah melihat kedatangan Hang Tuah dengan terkejut ia tersurut beberapa langkah lalu dengan bimbang Ia berkata)

Apakah tuan Hang Tuah?

Tiadakah Hang Tuah telah binasa.

Hang Jebat masih ragu dengan Hang Tuah karena setahu Hang Jebat Hang Tuah telah tiada.

\subsection{Hang Tuah :}

Ajal terletak di tangan tuhan

Sebelum ajal pantang mati.

Data di atas Hang Tuah mengatakan dengan tegas dan meyakinkan pada Hang Jebat bahwa ia masih hidup. Belum mati seperti yang diberitakan orang.

\subsection{Hang Jebat :}

Kalau benar engkau Hang Tuah

Apa maksudmu kemari.

Hang jebat sudah yakin bahwa Hang Tuah masih hidup karena itu Ia bertanya apa maksud kedatangan Hang Tuah ke istana. 


\subsection{Hang Tuah :}

Adakah kau lihat sumpah kita berlima saudara.

Mengabdi sepanjang umur

Bersetia sampai mati.

Data di atas menjelaskan bahwa sekali lagi Hang Tuah mengingatkan kepada Hang Jebat tentang sumpah lima bersaudara pada masa lalu, mengabdi sepanjang umur bersetia sampai mati sumpah ini harus dipertahankan terus

\subsection{Hang Jebat :}

Raja adil Raja di sembah

Raja lalim Raja di sanggah

Kalau hukum jadi permainan

Tiada si Jebat mau setia.

Hang Jebat dengan tegas membantah bahwa ia tidak lagi setia kepada raja.

\subsection{Hang Tuah :}

Dengki khianat adat hidup jebat, Lupa dan khilaf pakaian manusia Tetapi mendurhaka pada Raja

Bukan tanggung tanggung dosanya.

Berdasarkan data di atas Hang Tuah mengingatkan lagi kepada Hang Jebat, bahwa perbuatan mendurhaka kepada Raja adalah dosa yang amat besar.

\subsection{Hang Jebat :}

Bersunguh-sungguhkah orang kaya mau bertikam dengan hamba.

Hang Jebat tak bisa lagi dinasehati oleh Hang Tuah, ia langsung menantang Hang Tuah untuk bertarung secara ksatria Melayu.

\subsection{HANG TUAH :}

Pantang panglima mengulang langkah surut, Pantang memandang sanak famili,

Yang benar dibenarkan jua

Yang salah tetap salah di mata hukum.

Hang Jebat tentu saja terpancing dengan kata kata Hang Tuah, bahwa ia juga sudah siap untuk melawan Hang Tuah dan tidak akan mundur selangkahpun dan siap bertarung.

\subsection{Hang Jebat :}

Kalau begitu, kata orang kaya, baiklah, tunggulah sebentar, Hamba mau melanggir keris Tameng Sari orang kaya ini sebentar (lalu dengan ganas Hang Jebat mengamuk dalam istana itu semua dayang dayang yang ada dibunuhnya. Jerit pekik bertalu darah mengucur sepanjang lantai)
Hang jebat marah dengan Hang Tuah, kemarahan tersebut ia lepaskan kepada dayang dayang yang ada di istana.

\subsection{Hang Tuah :}

Hai Jebat.

Perbuatan laknat apakah yang kau lakukan itu?

Data dia tas menjelaskan Hang Tuah membentak marah dengan Hang Jebat, mengapa membunuh dayang dayang yang tak bersalah itu.

\subsection{Hang Jebat :}

Ha......... ha........

Inilah perbuatan yang sempurna, orang kaya.

Sepalang palang bernama jahat jangan kepalang

Seperti kata pantun melayu

Rusak bawang ditimpa jambak

Rusak santan sebelanga oleh nira setotik

Biarlah Jebat bergelimang darah...

(tertegun dan muram)

Saudaraku Hang Tuah

Tahukah engkau mengapa kerja hamba laksamana.

Hang Jebat bersikap dengan tegas bahwa ia tak mau tanggung- tanggung berbuat jahat. Sebab menurut Hang Jebat ia membela keadilan dan kesetiaan demi saudara sepeguruannya Hang Tuah.

\subsection{Hang Tuah :}

Hamba , segala galanya hamba tahu

Kemurnian jiwa anak melayu.

Tetapi jangan karena aku,

Engkau durhaka kepada Raja.

Kutuk tertimpa atas kepala

Turun temurun jadi sebutan.

Data di atas menjelaskan Hang Ttuah sekali lagi mengingatkan kepada Hang Jebat bahwa kita sebagai anak Melayu tidak boleh melawan kepada baginda Raja. Kita harus setia kepada adat istiadat Melayu secara turun temurun sejak dahulu kala. Kepada baginda Raja kita tidak boleh durhaka. Hal tersebut akan terkutuk dan menjadi sebutan sepanjang zaman di masyarakat Melayu. 


\subsection{Hang Jebat :}

Kalau engkau sudah tahu,

Senanglah hatiku

Akan sekarang ini, apa takdir hamba nantikan.

Kalau si jebat binasa di tanganmu,

Kematian karena membela keadilan

Kesetiaan pada saudaranya.

Tetapi Hang Jebat punya pendapat yang lain, ia merasa tidak bersalah karena ia membela kebenaran dan keadilan setia kepada saudaranya Hang Tuah karena itulah yang menjadi alasan Hang Jebat mendurhaka kepada raja.

\subsection{Hang Tuah :}

Jebat, serahkan senjatamu.

Atas dosamu hambalah menanggungnya

Kepada raja.

\subsection{Hang Jebat :}

Wahai orang kaya laksamana

Bukankah adat kita sejak dahulu,

Tiada mengenal menyerah.

Senjata adalah nyawa ke dua di tubuh kita

Hilang nyawa di badan

Baru senjata terlepas di tangan.

Hang Jebat punya sikap yang tegas pula bahwa ia tidak akan menyerah pada Hang Tuah. Senjata adalah sama dengan kekuatan dan nyawa yang ada di badannya dan tidak boleh lepas dari tangannya.

\subsection{Hang Tuah :}

Baiklah Jebat.

Kita berjalan di persimpangan,

Tertumbuk dalam tugas

Kalau tidak sama binasa

Salah seorang kita gugur.

Hang Tuah sudah berusaha membujuk hang jebat tapi tidak berhasil. Maka dengan tegas pula Hang Tuah mengatakan sama sama punya prinsip yang harus di selesaikan dengan pertarungan, salah satu mesti ada yang gugur, hanya itulah penyelesaiannya.

\subsection{Hang Jebat :}

Naiklah orang kaya

Di istana kita bertikam.

Hang jebat menantang Hang Tuah untuk

bertarung di dalam istana dengan menyuruh Hang Tuah naik ke atas lantai istana.
3. 24 Hang Tuah : Bukakan aku pintu !

Hang tuah pun menyambutnya dengan kesatria melompat ke pintu istana. Untuk bertilkam dengan Hang Jebat. Terjadilah perkelahian antara keduanya di dalam istana.

\section{Simpulan}

Dari pembahasan $\mathrm{di}$ atas tentang pertarungan Hang Tuah dan Hang Jebat, pada masa kerajaan Melaka itu dapatlah kita mengambil simpulan. Apapun alasannya ketika Hang Jebat melawan kepada sultan dan kerajaan . Maka hal ini tidak dapat kita benarkan sikap melawan tersebut. Karena ia telah menghancurkan wibawa dan marwah kerajaan Melaka. Dengan mengamuk di istana, berarti ia menjatuhkan simbol simbol yang ada di kerajaan Melayu itu. Ia bisa saja tidak senang cara- cara sultan memerintah tetapi haruslah dengan cara yang santun memberikan kritik dan sarannya. bukan dengan cara cara yang liar seperti itu yang telah melanggar adat istiadat melayu yang penuh dengan kesantunan sesuai dengan ajaran Islam, adat bersendikan syarak, syarak bersendikan kitabullah. Jadi, tidak salah kalau Hang Tuah turun tangan untuk meredam amuk Hang Jebat di istana yang banyak membunuh korban yang tidak bersalah. Atas perintah sultan untuk menyelamatkan keutuhan kerajaan Melaka dan rakyat yang ada di kerajaan itu.suka atau tidak suka Hang Jebat mestilah dilumpuhkan. Dan di kalangan masyarakat melayu secara umum, Hang Jebat tetaplah dianggap pendurhaka di dalam pandangan masyarakat Melayu, baik di semenanjung Melayu Malaysia maupun Melayu Riau.

\section{Daftar Pustaka}

A'dzam Shuhuf, Sulong. 2016. Risalah Jebat. Pekanbaru : Tirta Kencana.

Darmawi, Ahmad. 2005. Teater Bangsawan Melayu Riau. Pekanbaru : LSBM-STR.

Kelana,Raja Ali. 1983. Pohon Perhimpunan. Pekanbaru: Bumi Pustaka.

Semi, M. Atar. 1988. Anatomi Sastra. Padang : Penerbitan Angkasa Raya Padang

Sumardjo jakob, 2004. Perkembangan Teater Modern dan Sastra Drama Indonesia, Bandung. STSI PRESS.

Tenas Effendi, 1984. Kumpulan Naskah Drama Daerah Riau, Pekanbaru, Proyek Pengembangan Kesenian Riau Departemen Pendidikan dan Kebudayaan. 
Zuriati, 2005, Jurnal Ilmu Budaya, Pekanbaru. Fakultas Ilmu Budaya Universitas Lancang Kuning.

W S, Hasanuddin, 1991 . Mitos dan Kontra Mitos Dalam Kreatifitas Sastra, Taman Budaya Pekanbaru 